
LA-UR-95-

TITLE: SHOCK INITIATION OF PBX-9502 AT ELEVATED TEMPERATURES

AUTHOR: Roberta N. Mulford and Robert R. Alcon, DX-10, LANL Los Alamos, NM 87545

SUBMITTED TO: 1995 APS Topical Conference on "Shock Compression of Condensed Matter" August 13-18, 1995 - Seattle, WA

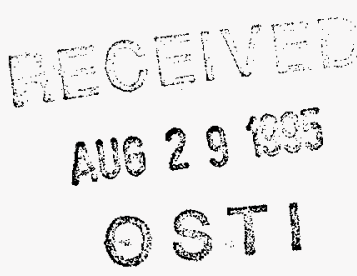

DISTRIBUTION OF THS DOCUMENT IS UNLIMTED JG

By acceptance of this article, the publisher recognizes that the U.S. Government retains a nonexclusive, royalty-free license to publish or reproduce the published form of this contribution, or to allow others to do so, for U.S. Government purposes.

The Los Alamos National Laboratory requests that the publisher identify this article as work performed under the auspices of the U.S. Department of Energy.

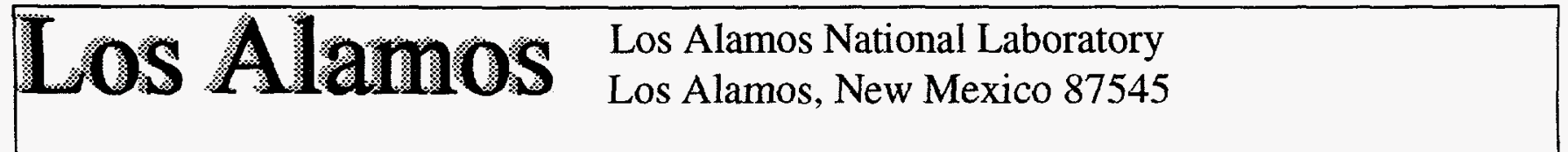




\section{DISCLAIMER}

Portions of this document may be illegible in electronic image products. Images are produced from the best available original document. 


\title{
SHOCK INITIATION OF PBX-9502 AT ELEVATED TEMPERATURES
}

\author{
R. N. Mulford and R. R. Alcon \\ Los Alamos National Laboratory, Los Alamos, New Mexico 87544
}

\begin{abstract}
The shock sensitivity of PBX-9502 is known to change with temperature. Both volume expansion and increased internal energy may contribute to this phenomenon. PBX-9502 was heated and its initiation and detonation behavior was examined, using MIV and shock tracker gauging on a light gas gun. Sensitivity and reactive wave profiles were measured. Complementary experiments were done on PBX-9502 made to undergo "ratchet growth", or non- reversible anisotropic thermal expansion, under carefully controlled thermal cycling. This process causes noticeable size changes and significant changes in sensitivity. Sensitivity and reactive wave profiles are discussed in terms of density and microscopic material morphology.
\end{abstract}

\section{INTRODUCTION}

TATB-based explosive PBX-9502 exhibits interesting thermal behaviors that may be expected to influence the sensitivity of the material at elevated temperatures. Both morphological and chemical changes may be important in understanding the response of $\mathrm{PBX}-9502$ at temperatures above ambient.

Morphological changes include alteration in size and distribution of hotspots and a decrease in initial density with increasing temperature. On heating, TATB-based explosives undergo "ratchet growth," or non-reversible thermal expansion, as a result of grossly anisotropic thermal expansion of TATB crystallites in the material. The phenomenon is complicated, with the material exhibiting several different growth regimes at different temperatures, 1 due to interactions of crystallites and binder behavior. As the crystallites and binder are expanded and redistributed, intercrystalline porosities are believed to decrease, while intracrystalline porosities are believed ${ }^{2}$ to increase, both of which may be expected to influence initiation properties.

Dependence of reaction rate on temperature almost certainly increases the reaction of the TATB at elevated temperatures, although extensive experiments by Buntain ${ }^{3}$ have shown the increase in reactivity with increasing temperature to be small.

\section{EXPERIMENT AL}

Experiments are done on a single stage light gas gun, using in-material magnetic (MIV) gauging $4,5,6$ in a target specially modified to allow controlled heating and temperature monitoring.

The target is heated front and back using silicone rubber flexible heaters ${ }^{7}$ rated to $45 \mathrm{~W}$ and $220^{\circ} \mathrm{C}$. The entire target was insulated with household fiberglass insulation. Temperature was monitored at 4 locations including the gauge plane, using both wire and fine foil 8 copper constantan thermocouples. Thermocouple mortality was high during heating, possibly due to expansion of the PBX material onto which the TC was fastened. One minute before firing, the front heater and insulation was jettisoned using a spring assembly, to provide an unimpeded planar surface for projectile impact. Heating rates and temperature uniformity within the target were thoroughly studied, as was cooling after ejection of the front heater. Heating was performed at between 0.5 and $1^{\circ} \mathrm{C} /$ minute, to prevent thermal stresses, distortion, or cracking in the PBX material.

The gas gun generates reliably wellsupported shock waves with a well-characterized wave shape. The square pressure pulse simplifies consideration of the time-dependent behavior of the growth of the reactive wave. The gas gun can reach 
projectile velocities of up to $1.4 \mathrm{~mm} / \mathrm{usec}$, corresponding to pressures of up to about $10.5 \mathrm{GPa}$ in full-density PBX materials when single crystal sapphire impactors are used. This maximum pressure is insufficient to detonate cold PBX-9502 within the observable time, but if the material is hot or has undergone non-reversibie thermal expansion to a lower density, then the run to detonation will be short enough to provide good data. Particle velocity $u_{p}$ was measured directly using ten nested magnetic gauges, and shock velocity $U_{S}$ was obtained from time of arrival at the different gauges and from a shock tracker gauge. ${ }^{6}$

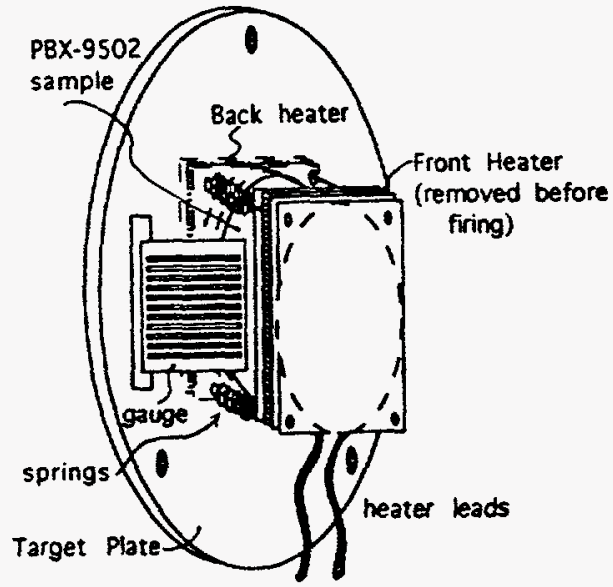

Figure 1. The hot MIV target

\section{DISCUSSION}

Heated material exhibits quite different reactive behavior from other detonable (HMX-based) PBX materials studied at these pressures. Waveforms observed in PBX-9502 at $80^{\circ} \mathrm{C}$ are shown in Figure 2. The mechanism for increased reactivity at high temperatures consists of two factors, temperature dependence of the reaction, and material morphology. These data confirm that significant changes in material morphologies occur between ambient and $100^{\circ} \mathrm{C}$, as has been proposed to explain anomalous thermal expansion and contraction data 1 .

Between $25^{\circ} \mathrm{C}$ and the pressing temperature of the material, which varies between $80^{\circ} \mathrm{C}$ and $100^{\circ} \mathrm{C}$, TATB crystallites undergo thermal expansion to reoccupy the voids created when they cooled and contracted after pressing. This process produces some net volume expansion, but is generally recognized ${ }^{2}$ to result in a decrease in porosity of the PBX material. Above the pressing temperature, further expansion of TATB crystallites pushes them apart. This "graphitic" growth along with increased flow of the binder increase the void fraction as the net volume increases rapidly. Porosity discussed here refers only to intercrystalline voids. It is anticipated that intracrystalline voids increase uniformly with temperature, but data is inconclusive.

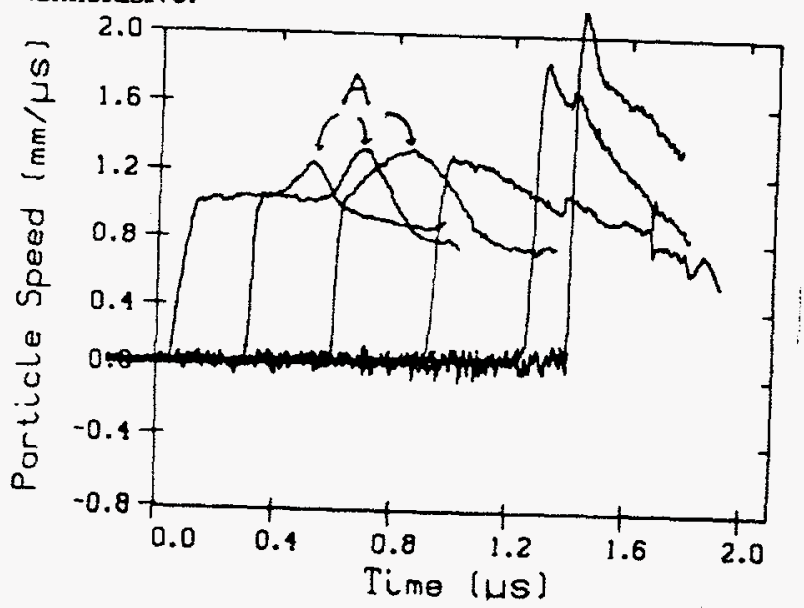

Figure 2. MIV gauge records for PBX-9502 reacting at $80^{\circ} \mathrm{C}$. Baseline drift due to an electronic artifact that has been corrected.

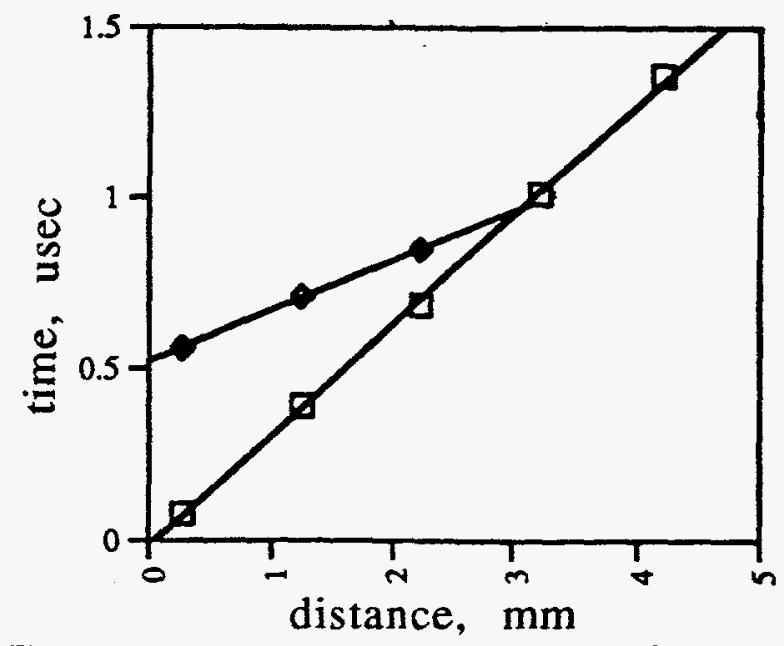

Figure 3. The $x-t$ diagram drawn from experimental data shows the overtake of the shock ( ) by the superdetonation. ( ) 
Material near the pressing temperature can thus be expected to have quite low intercrystalline porosity, resembling a very dense solid or a liquid. The development of detonation in the absence of hot spots relies on homogeneous initiation, ${ }^{9}$ in which the reactive wave or "superdetonation" arises in the hot shocked material after the shock front has passed, and then accelerates to join the shock front as a full detonation wave. The process is chemical, rather than mechanical. This "superdetonation" is clearly visible, marked " $A$ " in the $u_{p}$ records shown in Figure 2. The location of the reactive wave maximum is measured in each record, and the position of this wave is shown in the $x-t$ diagram shown in Fig. 3. Further examples of this behavior in liquids may be found in the literature. 10

At higher temperatures, the (intercrystalline) void fraction increases, restoring the material to a typical porous PBX, and the initiation to a homogeneous mechanism. The data shown in Figure 4 was taken at $100^{\circ} \mathrm{C}$, and shows $u_{p}$ profiles typical of heterogeneous initiation, comparable with that of room temperature HMX-based PBX materials.

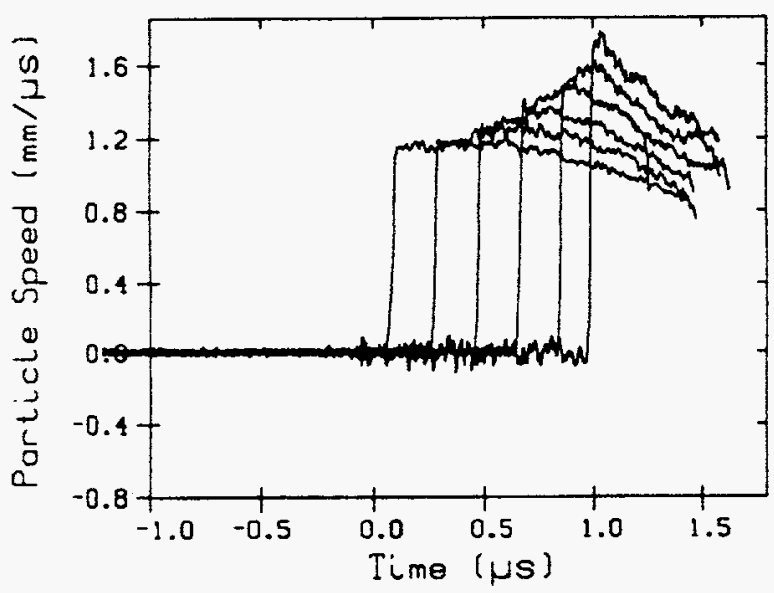

Figure 4. Detonation behavior of PBX-9502 at $100^{\circ} \mathrm{C}$.

These records are consistent with the expectation that the material morphology is altered in different ways as the material passes through different temperature regimes, and that detonation behavior depends strongly on the material morphology, specifically on intercrystalline voids.
A second explanation should be considered for these data. The detonation behavior of TATBbased materials has been suggested to be homogeneous, because the void size is small relative to the reaction zone of the TATB. In this case, the $80^{\circ} \mathrm{C}$ data may be viewed as an extension of the room temperature behavior. The records obtained at $100^{\circ} \mathrm{C}$ may be anomalous, resulting from microcracking during heating. This kind of microcracking has been seen ${ }^{11}$ in a few of many identical PBX-9502 samples subjected to the same very controlled heating. Microcracking has a marked effect on the growth of the reactive wave. A larger number of experiments will assist in distinguishing between these possibilities.

The apparent irrelevance of intracrystalline porosity to the initiation mechanism lends some support to the assertion that small voids do not assist in the hot spot initiation of the PBX-9502. However, the true behavior of intracrystalline voids with temperature is not well characterized.

The chemical contribution to the increase in reactivity at these elevated temperatures may be evaluated by comparison of the run distance for PBX-9502 at reduced density with the run distance vs. run time points for these heated samples. Plots are shown in Figure 5.

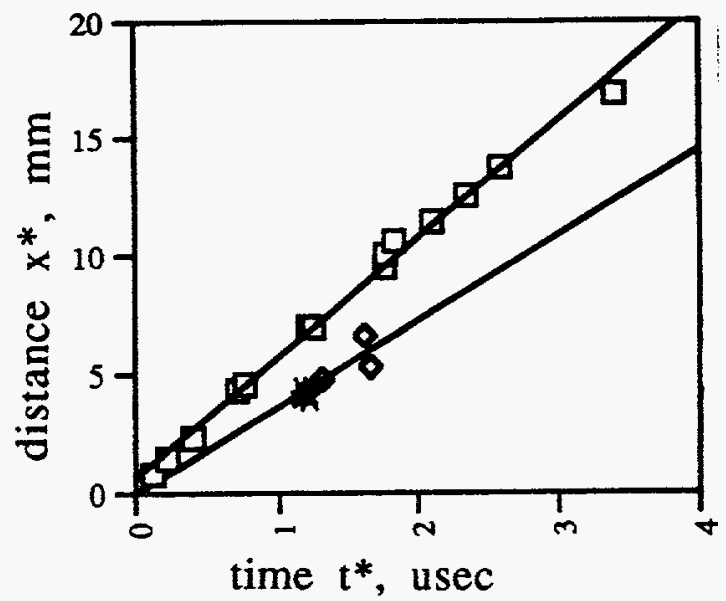

Figure 5. The run distance for the heated PBX-9502 sample (*) is comparable to the run distance for PBX9502 at initial density of $1.825(\diamond)$, but differs from the run for cold PBX-9502. (a) 
The points for reduced density material were obtained from shots done on cold PBX-9502 that had been subjected to ratchet growth by repeated heating in an oven to $2110 \mathrm{C}$, cooling very slowly to room temperature in between cycles. The resulting samples were then machined into MIV wedges and fired cold on the gas gun. Wackerle and Dallman ${ }^{2}$ show that the sensitivity of material expanded in this way does not differ from material pressed to the same reduced density, ruling out chemical decomposition during the heating cycles.

The density of the $80^{\circ} \mathrm{C}$ sample can be estimated 1,2 to be 1.848 , compared with 1.825 for the expanded material, allowing for the possibility that its reaction may be slightly accelerated by temperature in order for its run distance to fall with that of lower density material. Points for both hot and expanded PBX-9502 fall on the Hugoniot given by Dallman and Wackerle ${ }^{2}$ for PBX-9502 at $75^{\circ} \mathrm{C}$.

\section{CONCLUSION}

The rate of chemical reaction of TATB is increased with temperature, since the $80^{\circ} \mathrm{C}$ sample exhibits a shortened run distance despite the decreased porosity of the sample and the homogeneous initiation mechanism, which is independent of hot spots.

In the temperature regime above the pressing temperature, porosity increases and hot spot density and activity dominate the reaction, masking bulk thermal effects on chemical rate. The initiation mechanism in this case is heterogeneous.

The observation of increased chemical reactivity supports Wackerle and Dallman's ${ }^{2}$ proposal that those hot spots that are too small to cause significant reaction behind a given shock will, above a certain temperature, become effective and contribute to the initiation of the explosive.

The limits on the temperatures and porosities at which PBX-9502 will exhibit homogeneous initiation behavior will contribute interesting data to the understanding of hotspot reaction, yielding data on the interaction of chemical reaction rate and hotspot effectiveness.
1. Howard Cady, Los Alamos National Laboratory, M-1, informal report written to J. Dallman concerning high temperature materials property measurements on PBX-9502 and LX-17, May 1993.

2. J. Dallman and J. Wackerle, Tenth Symposium (International) on Detonation, \#110, July 12-16, 1993.

3. G. A. Buntain, Los Alamos National Laboratory, M1 , informal report written to J. Dallman, M-1, concerning the impact sensitivity of TATB powders at ambient, $250^{\circ} \mathrm{C}$, and $300^{\circ} \mathrm{C}$, June 1990 .

4. R. Mulford, S. Sheffield, and R. Alcon, in "High Pressure Science and Technology," Colorado Springs, 1993, p. 1405.

5. S. Sheffield and R. Alcon, in "High Pressure Science and Technology," Colorado Springs, 1993, p. 1405.

6. R. Mulford and R. Alcon, "Shock Tracker Configuration of In-material Gauge," this volume.

7. Watlow Corporation, $003030 \mathrm{Cl}$.

8. RDF Corporation, Hudson, New Hampshire.

9. A. W. Campbell, W. C. Davis, and J. R. Travis, Phys. Fluids 4, 498 (1961).

10. S. A. Sheffield, Ray Engelke, and R. R. Alcon, Ninth Symposium (International) on Detonation, p. 39 (1989).

11. R. Mulford, unpublished MIV records obtained from PBX-9502 subjected to thermal expansion and contraction. 


\title{
Shock Initiation of PBX-9502 at Elevated Temperatures
}

\author{
Roberta Mulford and Robert R. Alcon
}

\author{
Los Alamos National Laboratory
}

\section{to \\ 1995 APS Topical Conference on Shock Compression of Condensed Matter}

\author{
August 14, 1995 \\ Seattle, Washington
}

\section{DISCLAIMER}

This report was prepared as an account of work sponsored by an agency of the United States Government. Neither the United States Government nor any agency thereof, nor any of their employees, makes any warranty, express or implied, or assumes any legal liability or responsibility for the accuracy, completeness, or usefulness of any information, apparatus, product, or process disclosed, or represents that its use would not infringe privately owned rights. Reference herein to any specific commercial product, process, or service by trade name, trademark, manufacturer, or otherwise does not necessarily constitute or imply its endorsement, recommendation, or favoring by the United States Government or any agency thereof. The views and opinions of authors expressed herein do not necessarily state or reflect those of the United States Government or any agency thereof. 


\section{TATB Materials have \\ Complicated Thermal Behaviors}

* ratchet growth

* non-Arhennius sensitivity increase

* sensitivity decrease at high $\mathrm{T}$ 


\section{Morphology and Chemical Rate}

both affect Initiation of Hot Explosive
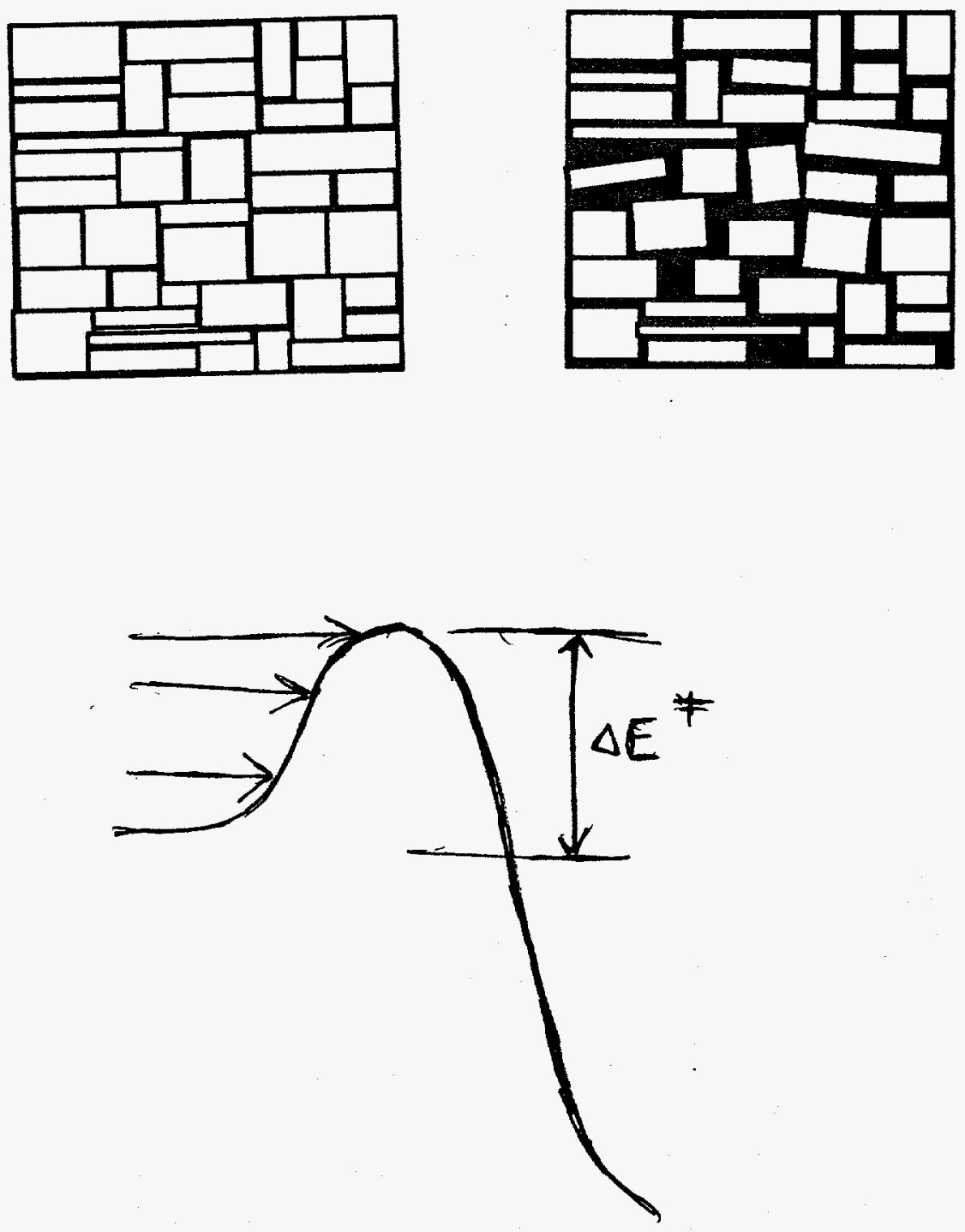
MIV Experiments are Done on the Gas Gun

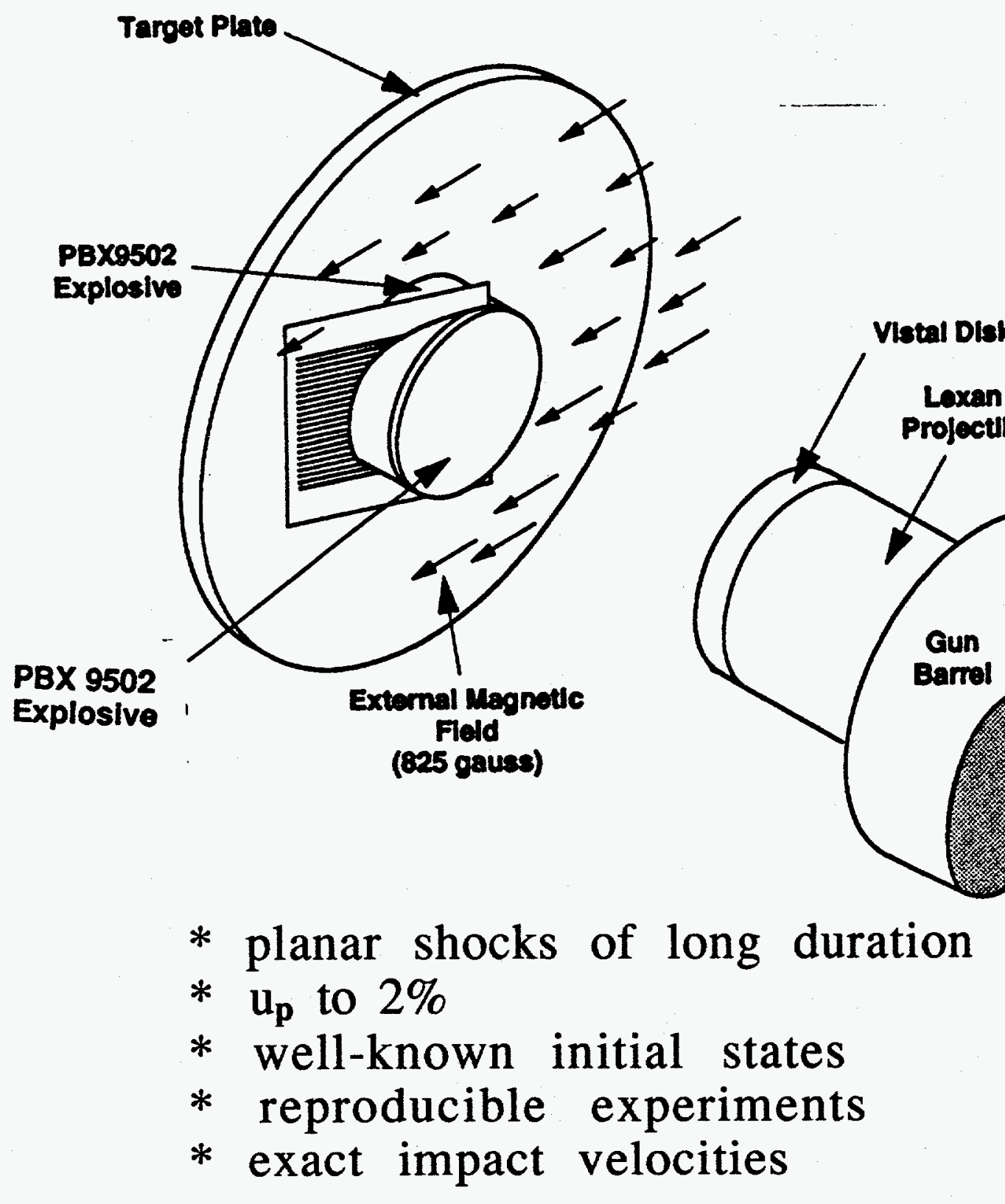


MIV Experiments are Done on the Gas Gun

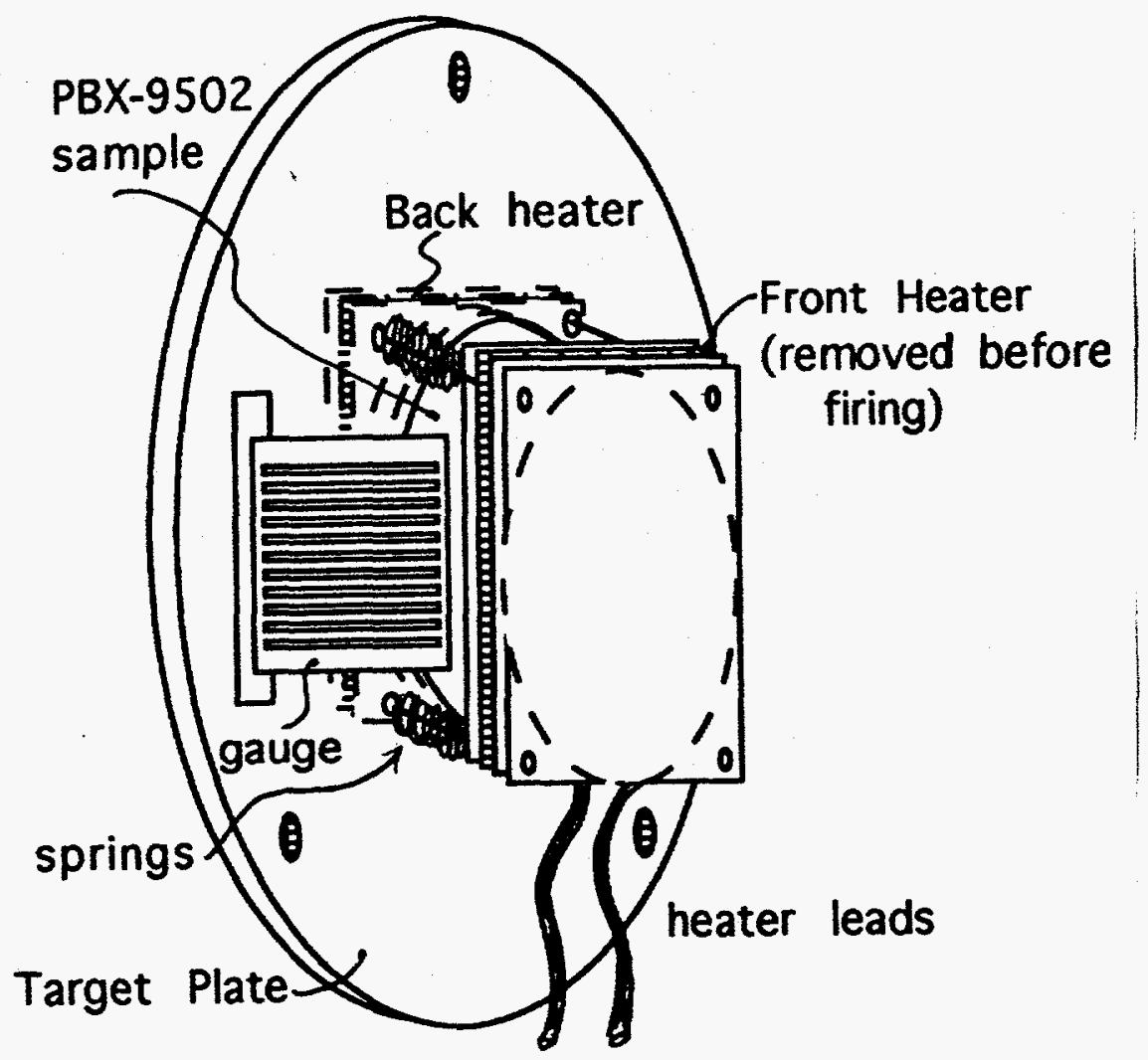

* planar shocks of long duration * $\mathrm{u}_{\mathrm{p}}$ to $2 \%$

* well-known initial states

* reproducible experiments

* exact impact velocities 
Densities and Porosities can be Estimated
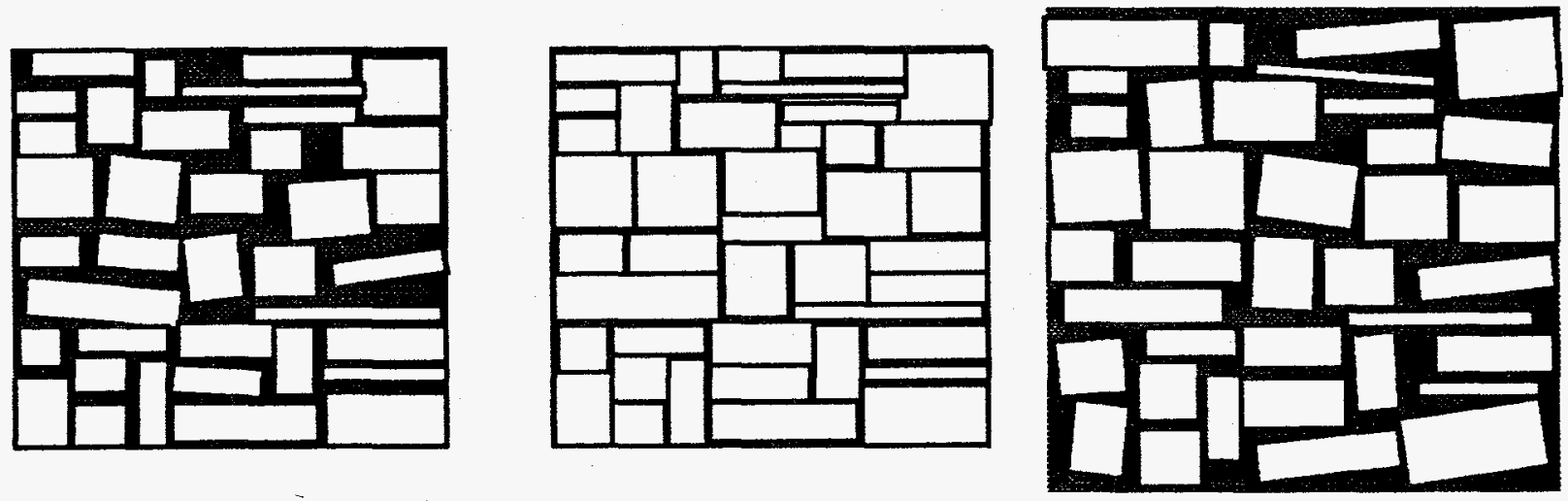

$250 \mathrm{C}$

$80 \mathrm{oC}$

$1000 \mathrm{C}$

PBX 9502 VOID PERCENT

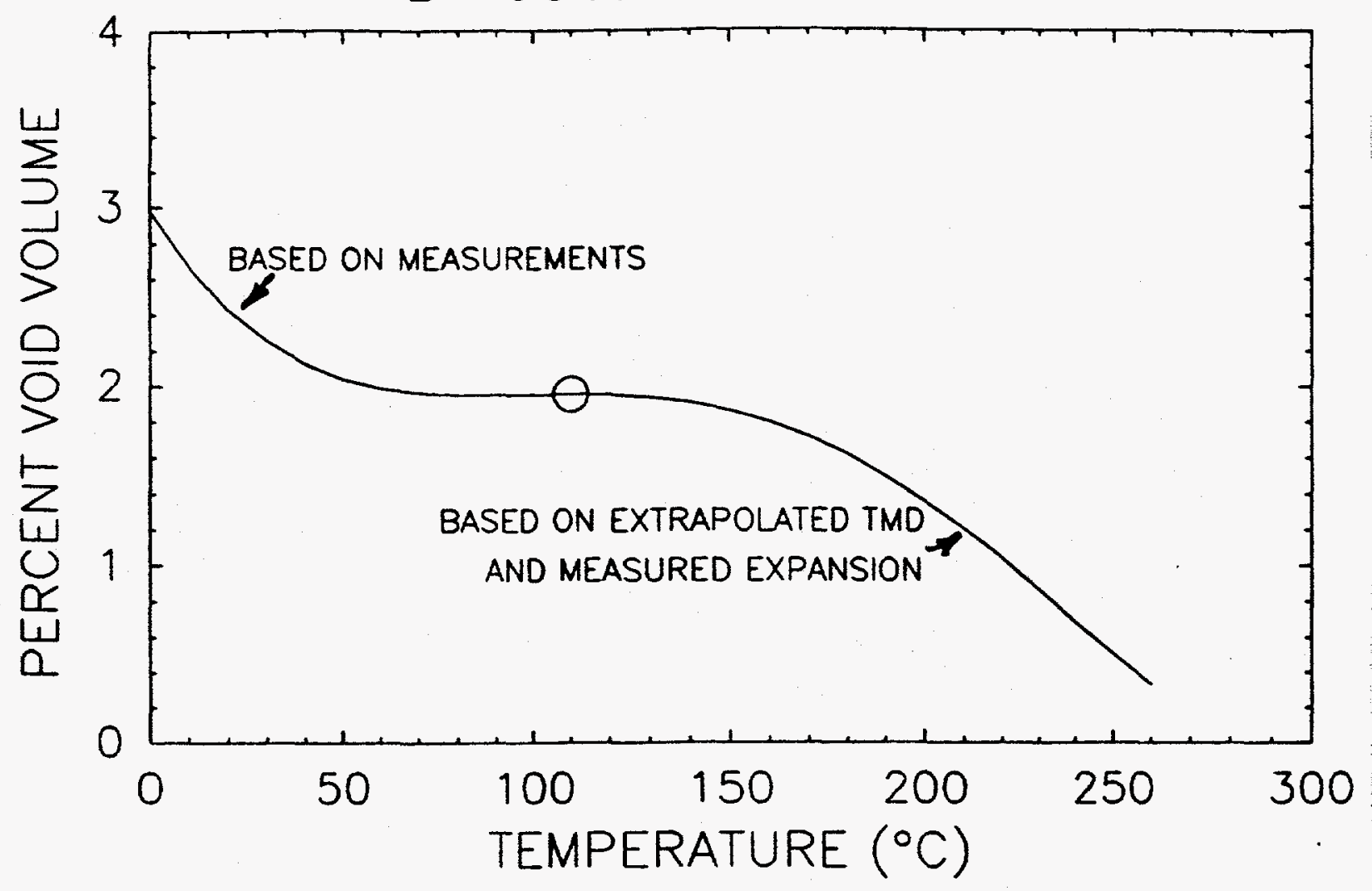

Howard Cady's extensive work 


\section{Homogeneous and Heterogeneous Initiation are distinguished in MIV records}
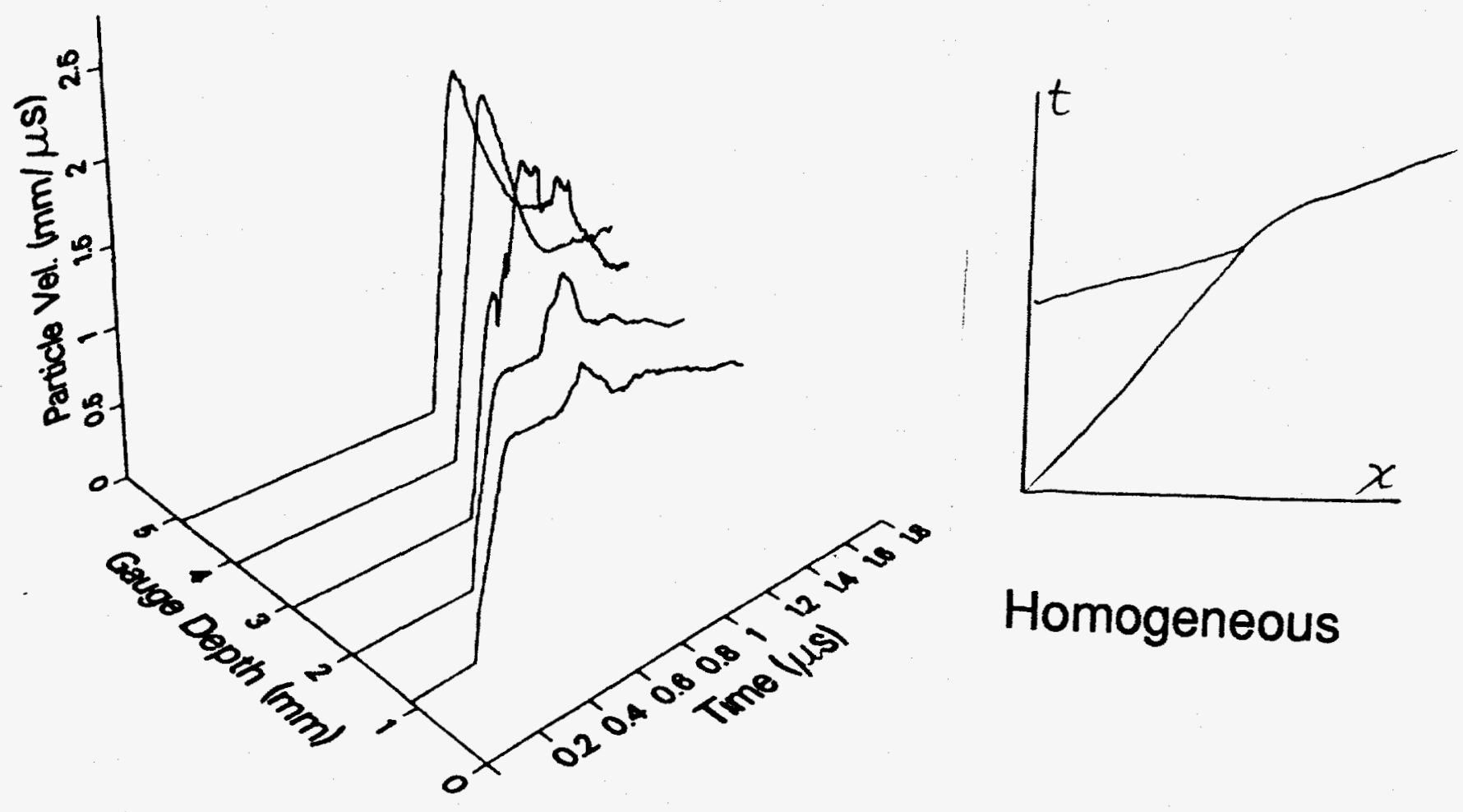

Homogeneous
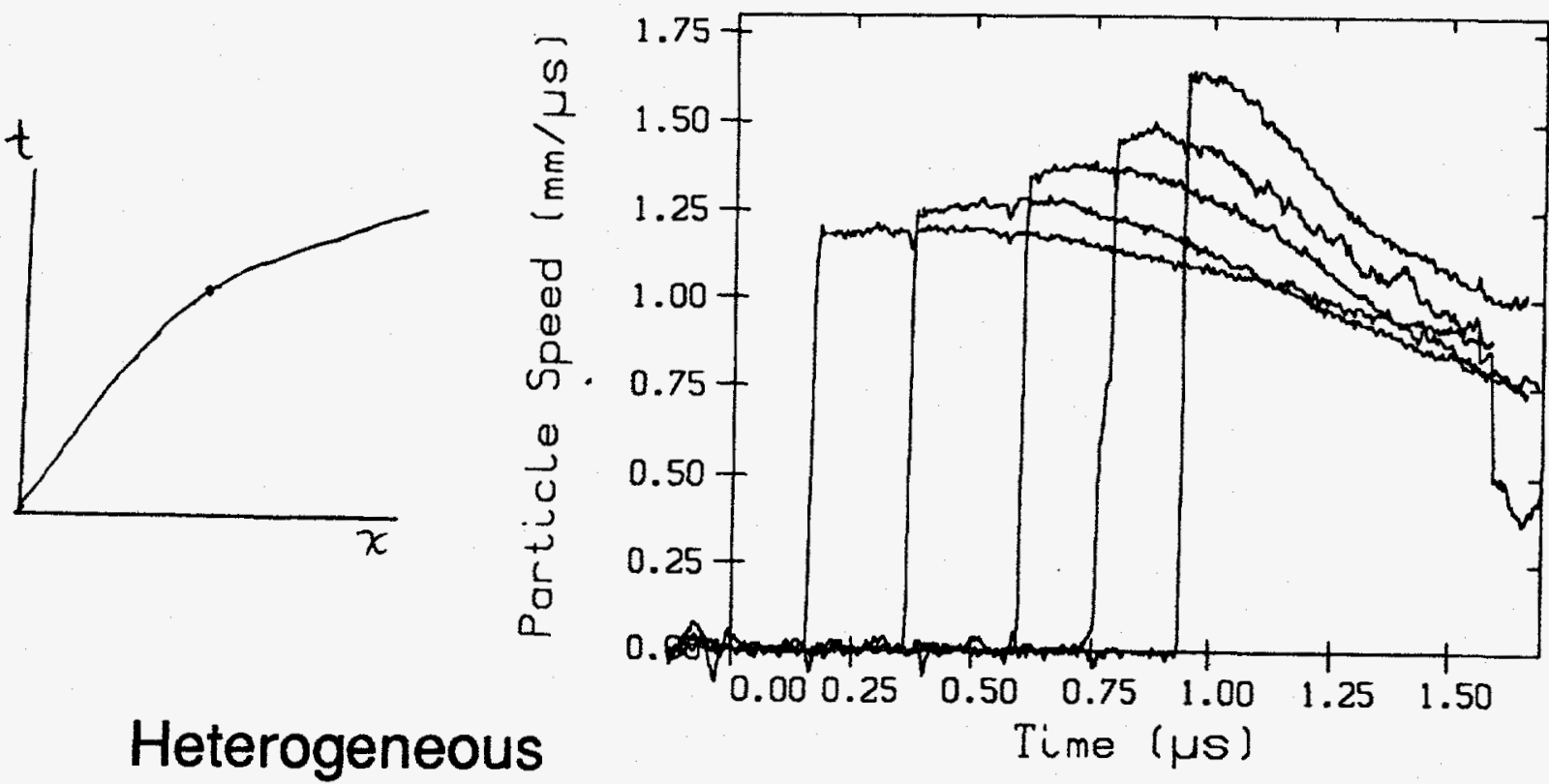

Heterogeneous

Time ( $\mu s$ ) 
PBX 9502 Initiation has Homogeneous character at $800^{\circ} \mathrm{C}$
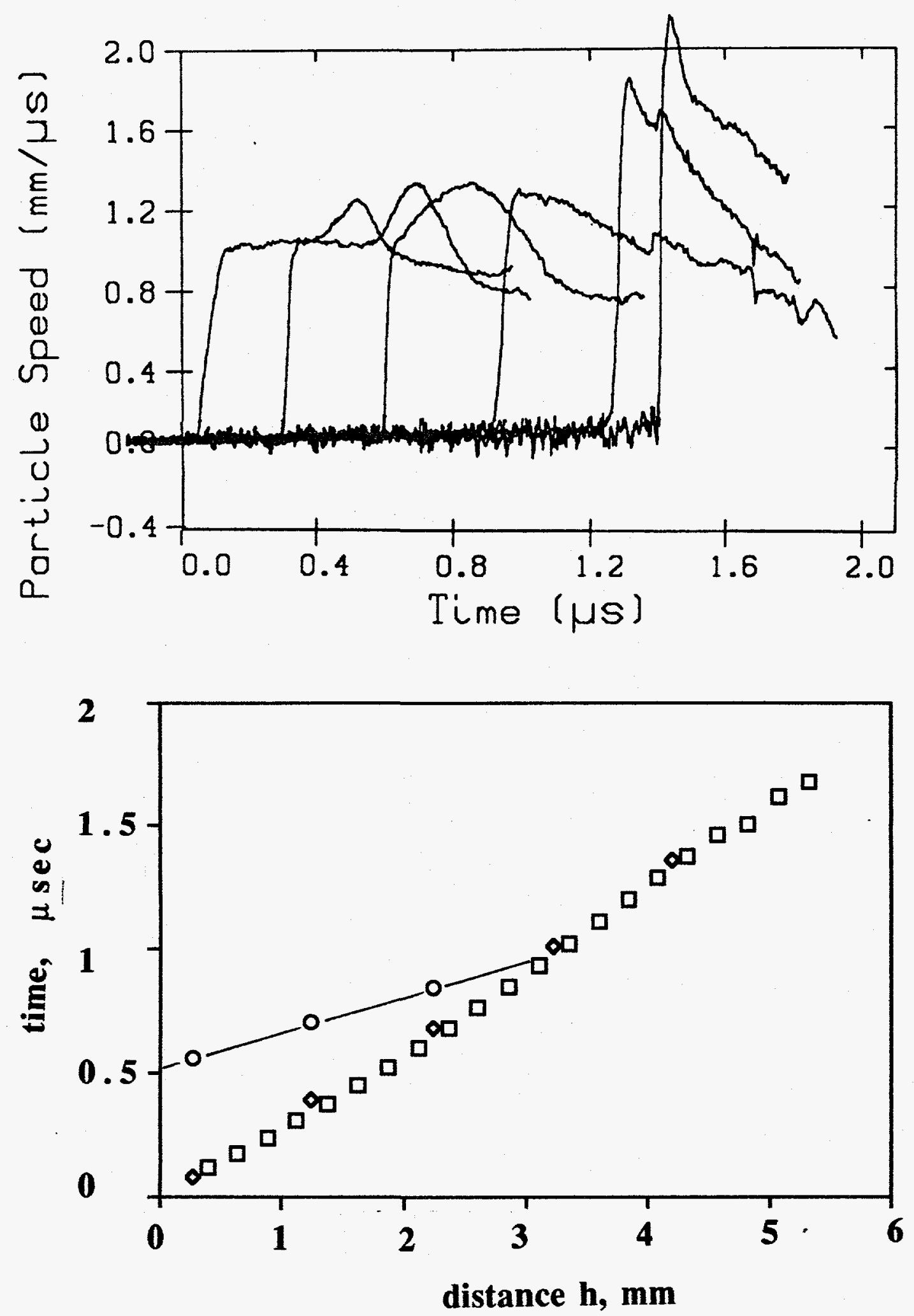


\section{Morphology at $80^{\circ} \mathrm{C}$ may Promote Homogeneous Initiation}
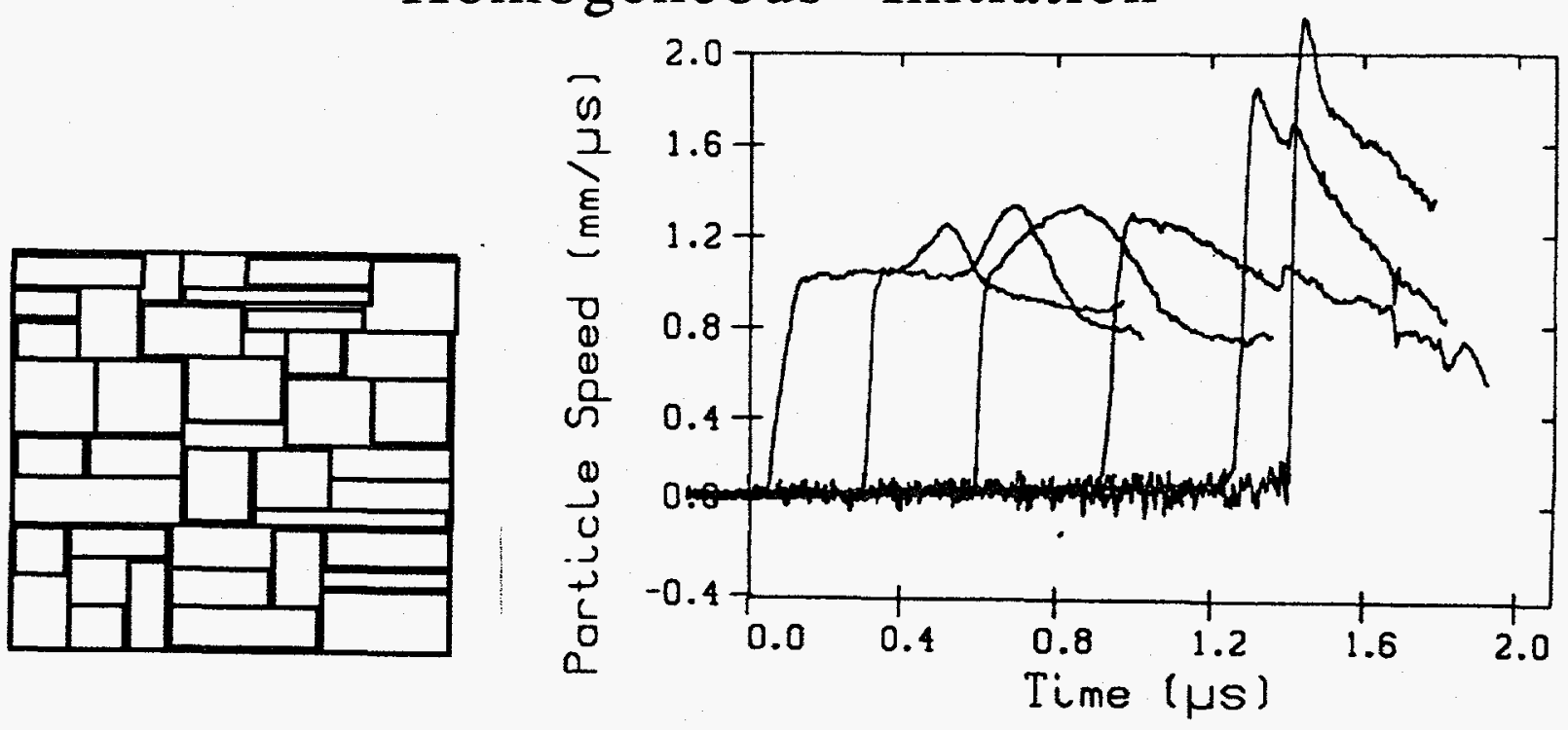

800C : few voids : homogeneous initiation
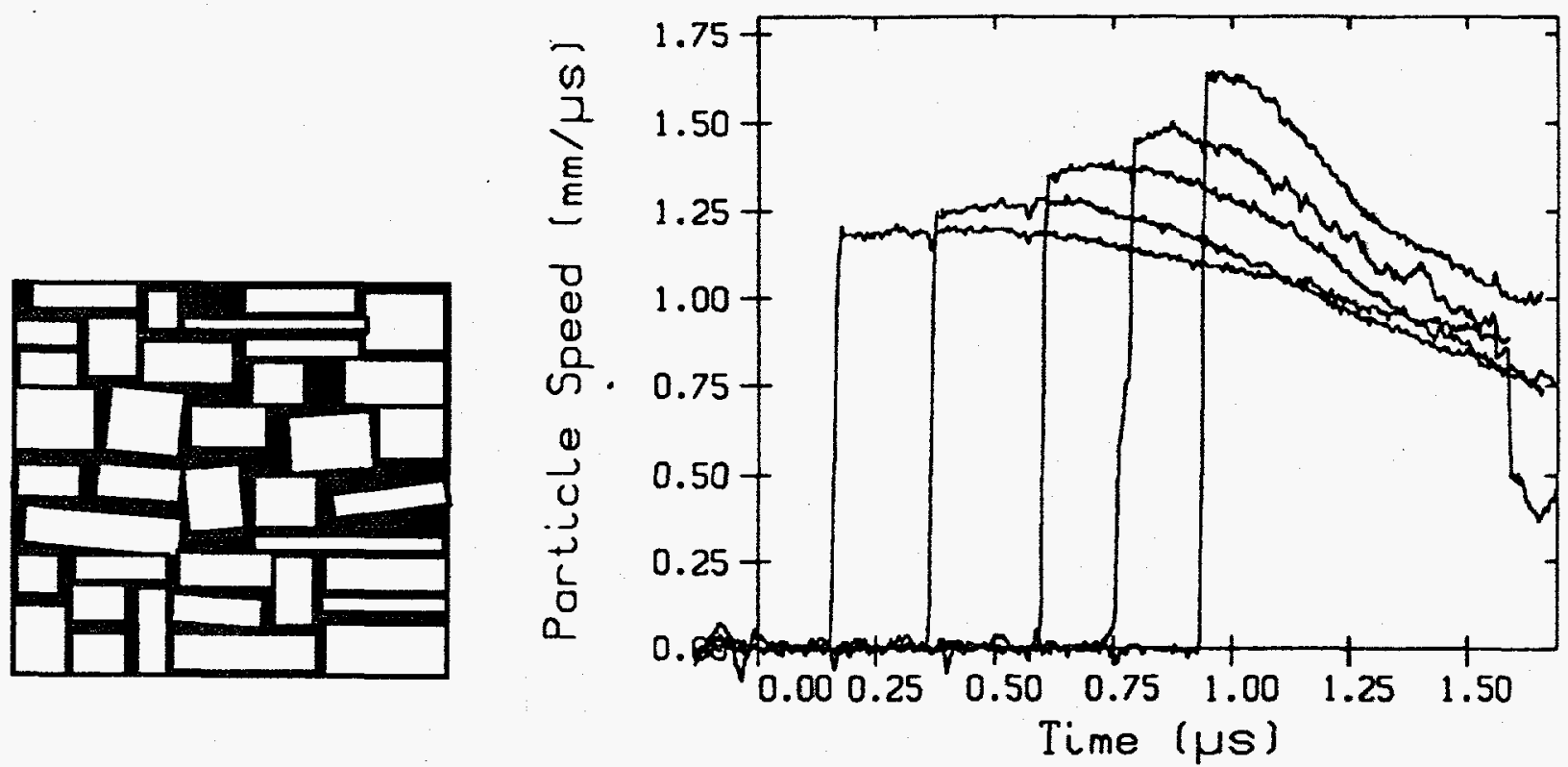

$250 \mathrm{C}$ : big voids : heterogeneous records 
Homogeneous Initiation may be typical of PBX 9502 at Any Temperature

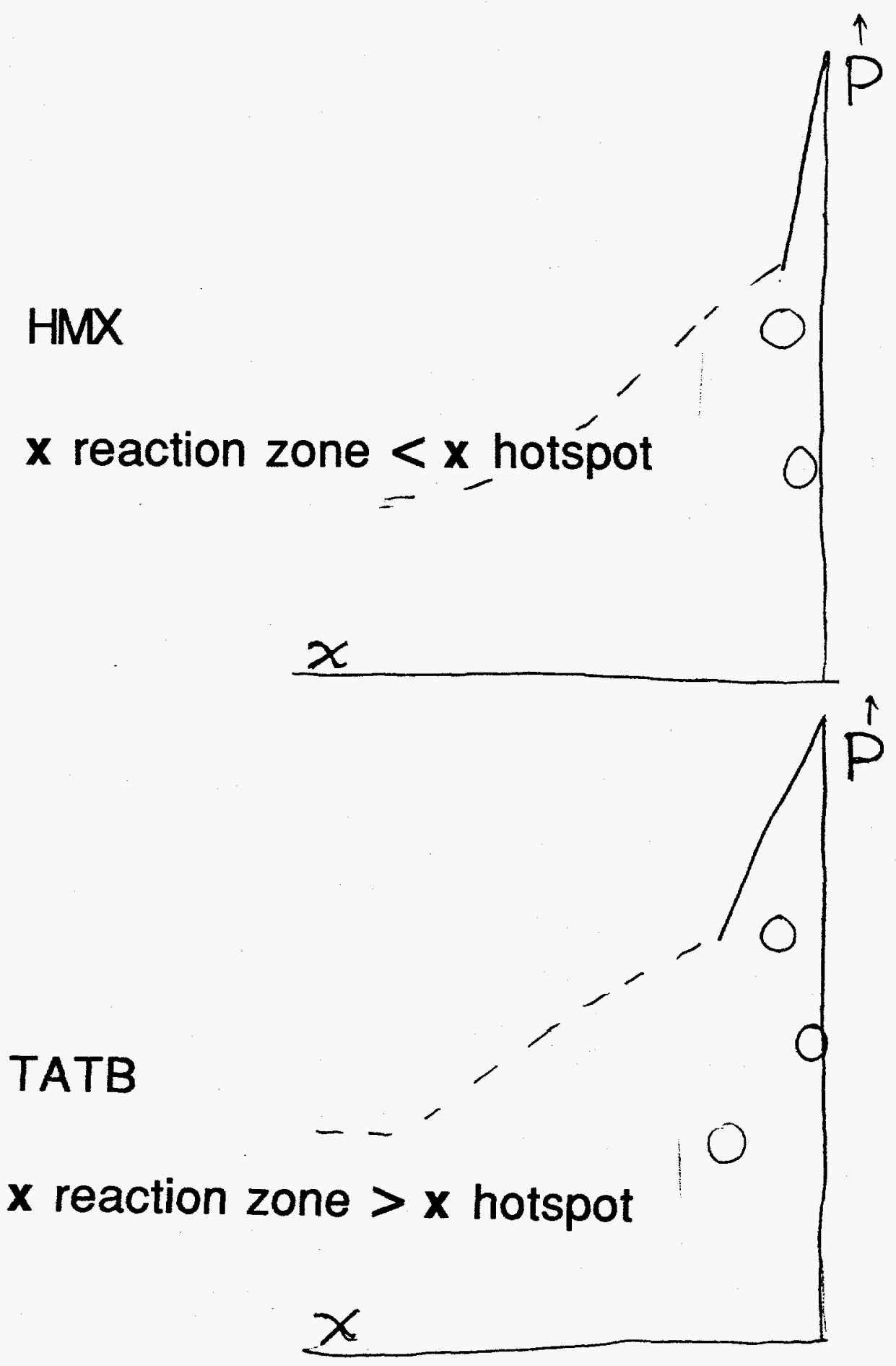




\section{Initiation at $1000^{\circ}$ looks Heterogeneous}

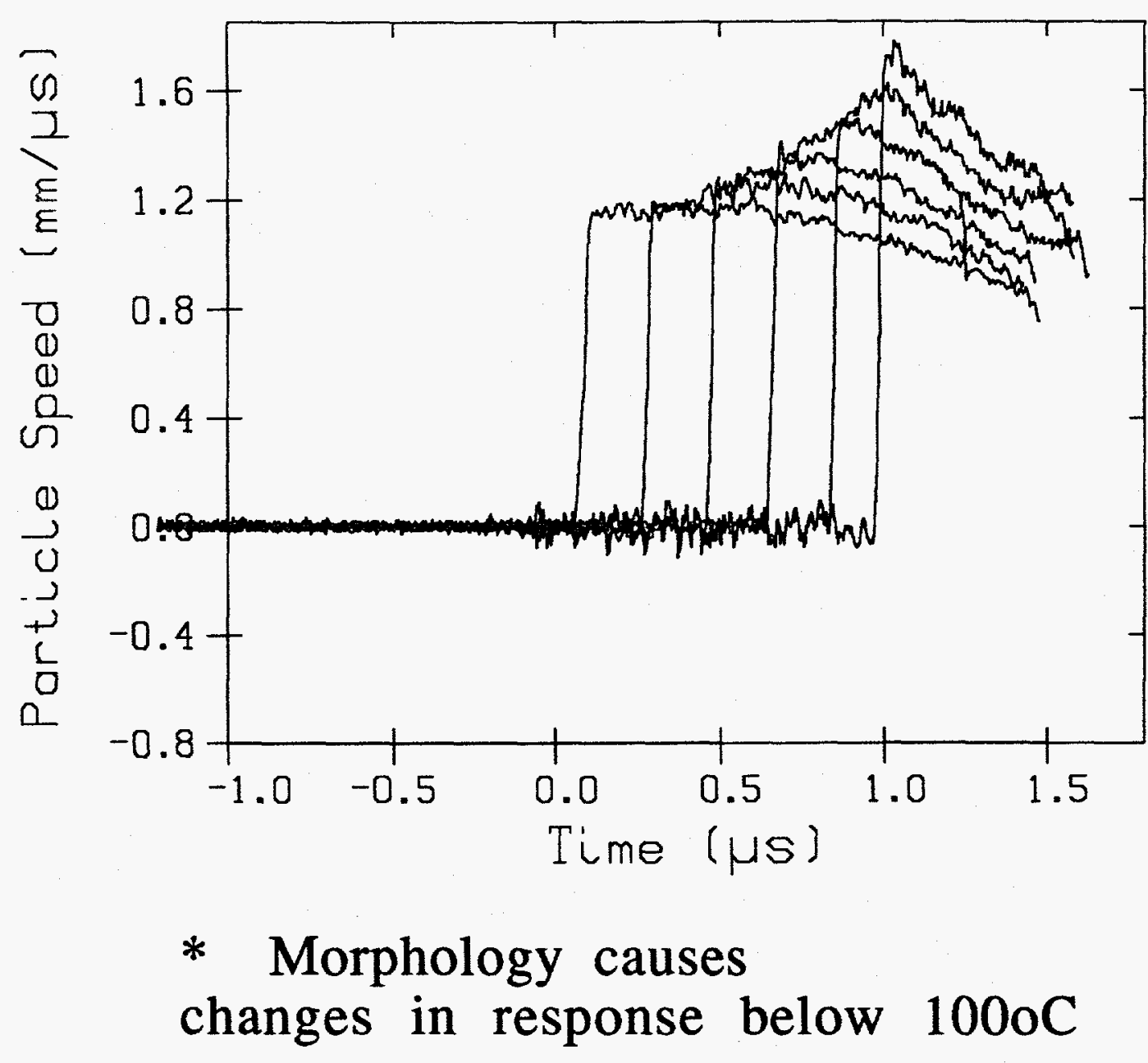


Chemical Response changes with Temperature

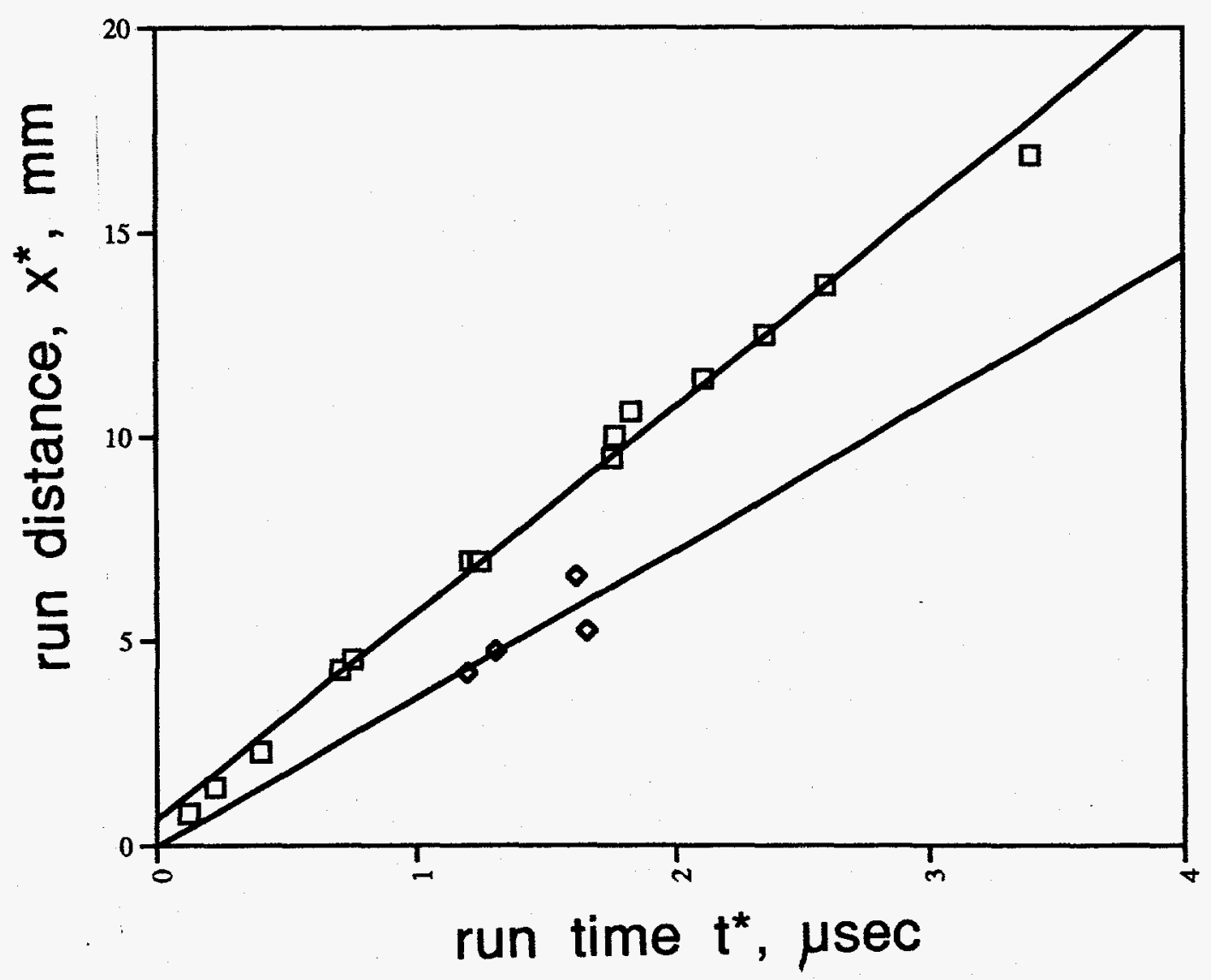

* unmasked by hotspot activity

* reaction accelerated, after correcting for density 
Mechanism of Reaction Varies between $25 \mathrm{CO}^{\mathrm{C}}$ and $100 \mathrm{OC}$

* dependent on pressing temperature

* chemical reaction increases with temperature

* porosity minimum may unmask chemical bulk rate effects 